

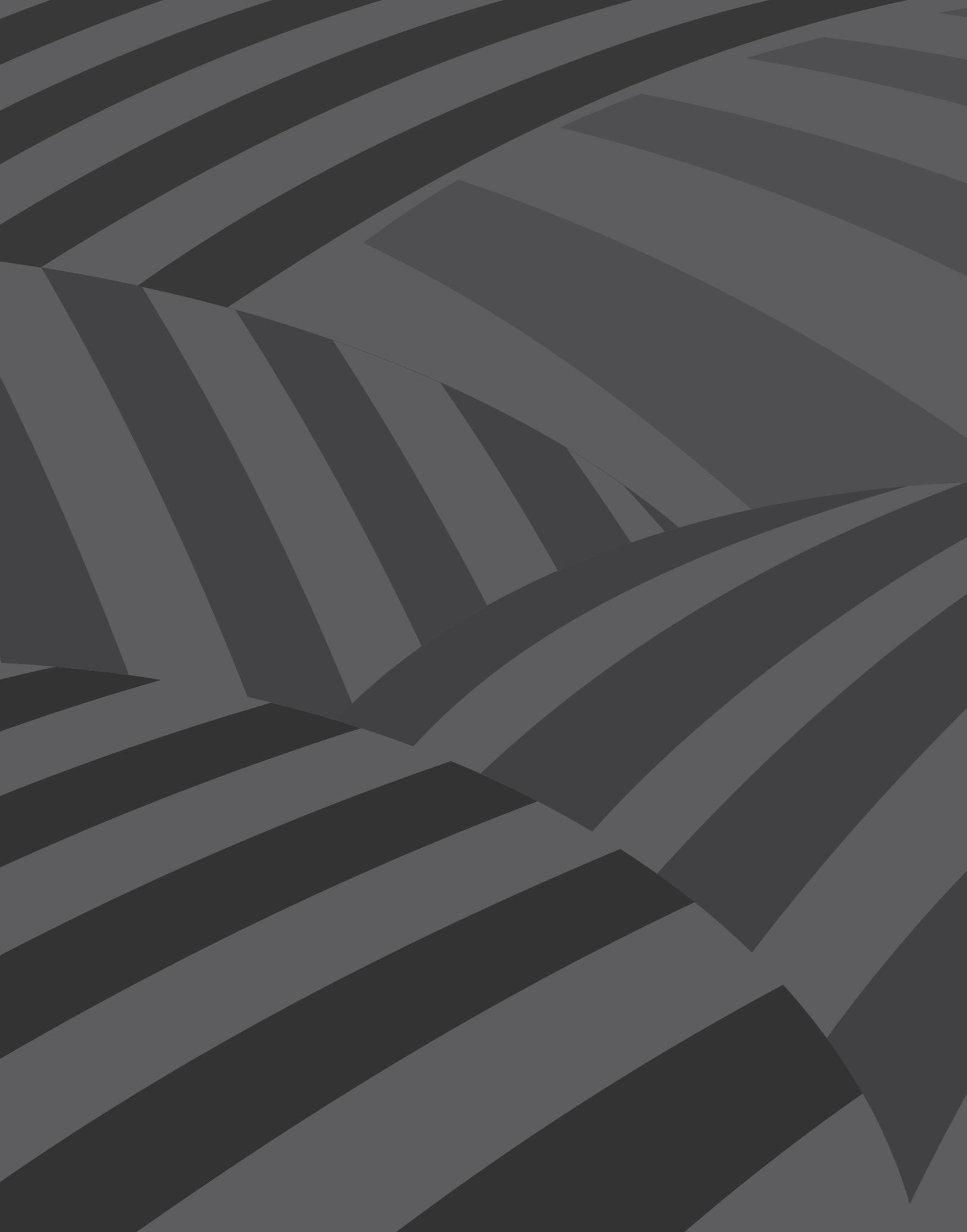




\section{Contrarrestando reclamos de democracia. El poder de las narrativas y la disputa por la jurisdicción en sectores extractivos en Colombia}

Por Kristina Dietz*

Resumen: El artículo está enfocado en el uso de narrativas para entender la manera como los reclamos de participación democrática en los conflictos por minería y extracción petrolera están siendo contrarrestados por actores del Estado y de las corporaciones. Teóricamente, el análisis está basado en una interpretación dialéctica entre narrativas y agencia, en la que las narrativas son entendidas como productos contingentes de interacción social. Se argumenta que para impedir la institucionalización de la participación democrática y evitar un cambio en las relaciones de poder en el sector minero y petrolero, se usa una combinación de diversas narrativas. Las narrativas principales son adaptadas a los reclamos de opositores, complementadas con nuevas historias en reacción a las condiciones cambiantes del contexto y combinadas para diferentes contextos, escenarios y públicos. Empíricamente, el estudio se enfoca en las disputas en torno a consultas populares por minería, fracking (fracturación hidráulica) y explotación de petróleo en Colombia. Los datos de análisis consisten en entrevistas semiestructuradas; transcripciones de dos audiencias públicas transmitidas en directo, una en el Senado de la República y otra en la Corte Constitucional; y varios artículos de dos de los principales periódicos colombianos: El Tiempo y El Espectador. El periodo investigado cubre desde junio de 2013 hasta noviembre de 2018.

Palabras clave: consultas populares, extracción de recursos, narrativas, jurisdicción, democracia, Colombia.

\section{Counteracting Claims for Democracy. The Power of Narratives and the Dispute over Jurisdiction in Extractive Sectors in Colombia}

Abstract: The article focuses on the use of narratives to understand how demands for democratic participation in mining an oil extraction conflicts are being countered by state and

* Politóloga, profesora e investigadora de la Universidad de Kassel y de la Freie Univeristät Berlin en Alemania. Sus areas de trabajo son extractivismo, conflictos, movimientos sociales y democracia. Correo electrónico: kristina.dietz@fu-berlin.de 
corporations. Theoretically, the analysis is based on a dialectical interpretation about narratives and agency, in which narratives are understood as contingent products of social interaction. It is argued that to prevent the institutionalization of democratic participation and prevent a change in power relations in the mining and oil sector, a combination of diverse narratives is used. The main narratives are adapted to the claims of opponents, complemented by new stories in reaction to the changing conditions of the context and combined for different contexts, scenarios and audiences. Empirically, the study focuses on disputes over popular consultations about mining, fracking (hydraulic fracturing) and oil exploitation in Colombia. The data analyzed came from semi-structured interviews, from transcripts of two public hearings transmitted live, one in the Senate of the Republic and one in the Constitutional Court, and from several articles from two of the main Colombian newspapers: El Tiempo and El Espectador. The period under investigation covers from June of 2013 to November of 2018.

Keywords: popular consultations, resource extraction, narratives, jurisdiction, democracy, Colombia.

Cómo citar este artículo: Dietz, Kristina (2019). Contrarrestando reclamos de democracia. El poder de las narrativas y la disputa por la jurisdicción en sectores extractivos en Colombia. Revista Controversia, 215, 277-310.

Fecha de recepción: 12 de noviembre de 2019

Fecha de aprobación: 13 de julio de 2020

\section{Introducción}

Desde el 2002, se han realizado a nivel municipal y provincial más de 100 consultas populares por minería y explotación de petróleo en seis países de América Latina (Walter y Urkidi, 2017; Dietz, 2018). Aunque reclamar la democracia parece no haber sido la razón original por la que se organizaron protestas, quienes aplicaron la consulta popular para detener un proyecto y expresar sus reclamos por "no haber sido consultados" o "escuchados", no obstante caracterizan estas consultas como "democracia en práctica” (Haarstad y Fløysand, 2007). En contraposición, actores del Estado nacional y de las corporaciones describen estos procesos principalmente como acciones ilegales o intervenciones ilegítimas de los ciudadanos o de un gobierno local en los asuntos políticos del Estado. Como resultado, el procedimiento de las consultas populares por minería, fracking (fracturación hidráulica) y explotación convencional de gas y petróleo se ha convertido en un asunto de conflicto en sí mismo (Hoetmer, 2010). 
En muchos casos de consultas populares celebradas exitosamente, los proyectos mineros o de hidrocarburos han sido temporal o completamente detenidos o rediseñados, o se han adoptado normas legales para prohibir la minería y la fracturación hidráulica en ecosistemas frágiles o territorios locales, al menos provisionalmente (Renauld, 2016; Christel, 2013; Delamata, 2013). Sin embargo, las disputas entre los varios niveles del Estado del sector de recursos mineros por las consultas populares, hasta ahora no han llevado a cambios institucionales de gran alcance que incluyan como meta una institucionalización completa de los derechos a la participación democrática o la redistribución del poder y de la jurisdicción.

Para entender cómo están siendo contrarrestados los reclamos de democracia, analizo las narrativas que emplean actores del Estado nacional y de las corporaciones para contradecir las peticiones de los actores que protestan o para lograr manejarlas de manera que sirvan a sus propios intereses (Moezzi, Janda y Rotmann, 2017). Por medio de las narrativas los actores dan significado a las realidades sociales, eventos y acciones. Las narrativas son entendidas como estrategias discursivas para ejercer poder; pueden tener potencial transformativo, pero también pueden contribuir a la restricción del cambio social. La pregunta por resolver es: ¿Cómo despliegan poder las narrativas para restaurar y estabilizar las relaciones políticas de poder? Sostengo que las narrativas son dinámicas, no operan aisladas y no son poderosas per se. Despliegan el poder si tienen impacto en las normas culturales y creencias del público y si se refieren a acciones sociales y eventos relacionados con el contexto.

Empíricamente, me enfoco en la disputa por las consultas populares en Colombia entre actores del Estado nacional - particularmente del Ministerio de Minas y Energía (MME), Agencia Nacional de Minería (ANM), Agencia Nacional de Hidrocarburos (ANH) y el presidente del país- y actores corporativos, por un lado, y las organizaciones no gubernamentales (ONG), organizaciones base y actores del Estado local, por el otro. Discrimino entre los actores del Estado local y nacional, ya que la 
línea entre grupos opuestos divide no solo a los actores estatales y no estatales, sino también a los estatales de diferentes niveles: nacionales y subnacionales o locales. El periodo investigado cubre desde junio de 2013 hasta noviembre de 2018, y fue seleccionado porque las interacciones públicas sobre las consultas populares entre campos opuestos comenzaron después de la primera consulta exitosa sobre minería, que ocurrió en julio del 2013. Desde entonces se han llevado a cabo nueve consultas populares jurídicamente vinculantes y una consulta autónoma por minería y explotación de petróleo. El 12 de abril de 2018 se realizó una audiencia pública en la Corte Constitucional sobre las consultas populares. Seis meses después, el 11 de octubre de 2018, las consultas populares locales por minería, explotación de petróleo y gas fueron declaradas ilegales por la Corte Constitucional, lo que representa una prohibición de facto de la consulta popular sobre temas relacionados con la extracción de recursos.

Al analizar las disputas entre los actores ya mencionados por causa de las consultas populares en Colombia, contesto la siguiente pregunta de investigación: ¿qué papel juegan las narrativas en la disputa sobre reclamos por la institucionalización de la participación democrática y la reproducción de relaciones de poder en el sector de recursos mineros? Teóricamente, el análisis está basado en la comprensión dialéctica de narrativa y agencia, de modo que las narrativas se entienden como productos contingentes de la interacción social (Tilly, 2002).

El artículo está estructurado de la siguiente manera. En la sección 2 expongo la metodología y los métodos de generación de datos y el análisis; en la sección 3 el marco teórico que sustenta el enfoque narativo; posteriormente (sección 4), presento un resumen de los eventos que ocasionaron las disputas sobre las consultas populares por extracción de recursos en Colombia. En el análisis (sección 5), identifico cuatro narrativas centrales utilizadas por los opositores de las consultas populares. Demuestro cómo estas emergieron en relación con eventos claves y a través de la interacción social, y analizo cómo se relacionan unas con otras para desplegar poder y contrarrestar los reclamos de democracia. En la conclusión, hago un resumen de los principales argumentos y 
resultados sobre cómo las narrativas emergen y despliegan poder en los conflictos sociales.

\section{Método y datos}

Los datos objeto de análisis provienen de tres tipos de fuentes. El primer tipo consiste en 17 transcripciones de entrevistas semiestructuradas que llevé a cabo durante siete visitas de investigación realizadas en marzo y septiembre de 2015, octubre de 2016, marzo y septiembre de 2017, y marzo y octubre de 2018. En ellas entrevisté a representantes de ONG, funcionarios del Ministerio de Minas y Energía y directivos de la compañía de minería AngloGold Ashanti (AGA), así como a abogados independientes, activistas en movimientos sociales y organizaciones de base, un alcalde y miembros de administraciones y concejos de tres municipalidades afectadas por la minería.

El segundo tipo de fuente son 103 artículos de dos periódicos importantes en Colombia - El Tiempo (83) y El Espectador (20) - que entre junio de 2013 y noviembre de 2018 cubrieron el tema de las consultas populares y citaron textualmente apartes de lo expresado por los protagonistas o los antagonistas. El tercer tipo contiene las transcripciones de las intervenciones orales de antagonistas y protagonistas durante dos eventos transmitidos en directo: un debate en el Senado de la República el 26 de septiembre de 2017 y una audiencia pública en la Corte Constitucional, titulada "Consultas populares locales sobre proyectos minero-energéticos”, la cual se realizó el 12 de abril de 2018. ${ }^{1}$ Ambos fueron grabados y luego parcialmente transcritos. Todos los textos fueron codificados y los elementos narrativos identificados inductivamente usando software de análisis cualitativo.

1 En adelante, el debate en el Senado se identificará con la sigla (DS) y la audiencia pública de la Corte Constitucional con la sigla (AP). 


\section{El enfoque narrativo}

Las narrativas son definidas como historias sobre eventos del pasado, contadas con el objetivo de interpretarlos, asignarles significado y orientar así las acciones. En los conflictos sociales, las narrativas se utilizan para articular quejas o reclamos, o para promover o defender intereses (Polletta y Chen, 2017; Verloo, 2018). Según Maarten A. Hajer (1997, p. 56), encontrar una narrativa - historia - apropiada "se convierte en una forma importante de agencia” durante un conflicto social. Un enfoque narrativo revela las historias con las que los actores dan sentido a lo que está en juego. Por su conocimiento, las personas recurren a las narrativas que tienen sentido para sí mismas, por ejemplo, en relación con sus valores, identidades, normas culturales, intereses, etc., en vez de referirse a “sistemas discursivos complejos” (Hajer, 1997, p. 56).

Para el objetivo de este análisis, las narrativas son entendidas como un medio para estudiar la manera como las reclamaciones de participación democrática popular son contrarrestadas por actores estatales y empresariales para lograr preservar y reproducir las relaciones de poder existentes en el sector de los recursos (Ewick y Silbey, 1995; Hajer, 1997). Por lo tanto, hago una distinción entre historias y narrativas. Entiendo las narrativas como expresiones de las historias en un sentido analítico; como tal, son interpretaciones analíticas producidas por la investigadora, en este caso yo misma (Verloo, 2018, p. 139; Abbott, 2008, pp. 15 y sigs.).

Desde una perspectiva dialéctica respecto a las historias y la acción, entiendo las historias como construidas siempre de manera interactiva, es decir, no emergen aisladas, sino que son productos que dependen de la interacción social. Las historias son fluidas y dinámicas, están incorporadas a las relaciones sociales de poder y atadas a un contexto específico. Surgen y cambian en relación con las historias de otras personas, acciones y eventos. Charles Tilly (2008, p. 8) subraya que las historias emergen del intercambio social activo: son ajustadas y modificadas como consecuencia del intercambio social y la acción, y, a su 
vez, pueden también restringir e influenciar la interacción social. Esto significa que no solamente es necesario preguntar lo que la gente dice, sino también lo que hace, ya que la narrativa y la acción social se constituyen mutuamente.

Las narrativas producen poder, pero todas las narrativas no son igualmente poderosas, ya que sus proponentes están insertados en relaciones sociales de poder. La posibilidad de que las narrativas sean poderosas depende de las identidades, valores, intereses, conocimiento y experiencias de los actores, y de la medida en que las narrativas de actores específicos resuenen con los paradigmas discursivos dominantes en un contexto determinado, que generalmente privilegia algunas estrategias discursivas, tácticas y declaraciones por encima de otras. Para entender cómo las narrativas funcionan y generan poder en conflictos sociales, es necesario analizar de qué manera las relaciones entre las historias cambian a lo largo del conflicto y cómo llegan a dominar una perspectiva sobre otra (Verloo, 2018, p. 139).

El poder de las narrativas depende de varios factores: los actores y sus posiciones sociales que fomentan/dan voz a las historias; la selectividad discursiva del contexto; la capacidad de las narrativas para adaptarse a los diferentes escenarios dentro de los cuales se narran las historias; la manera como son escuchadas y respondidas por el público y los destinatarios; la forma como resuenan con las normas culturales dominantes, los valores y las interpretaciones de amplio consenso; y cómo corresponden a las acciones realizadas por aquellos que narran historias y por los que cuentan historias opuestas. Dependiendo de estos factores, las historias tienen la capacidad de contribuir bien sea a cambiar el statu quo o a excluir puntos de vista contradictorios, contrarrestar reclamos y reproducir relaciones de poder (Verloo, 2018; Abbott, 2008).

Igualmente, Francesca Polletta y Pang Ching Bobby Chen (2017,pp. 10-16) sostienen que la estabilidad legal o las instituciones políticas dependen de la habilidad de promover historias que abordan y reproducen 
oposiciones binarias que son conocidas y aceptadas culturalmente, v. gr. hombre-mujer, naturaleza-cultura, intereses generales-intereses particulares, etc. Como ejemplo, Polletta (2006, p. 15) hace referencia a las historias de mujeres que supuestamente tienen aspiraciones de trabajo diferentes a las de los hombres; historias que solo tienen sentido en público porque se escuchan sobre el trasfondo de otras historias: las mujeres tienen una biología diferente a la de los hombres, los niños tienen gustos diferentes a los de las niñas. De acuerdo con el argumento anterior, el poder funciona no sobre una historia o narrativa única, sino a través de muchas historias diferentes situadas entre polos de oposiciones conocidas, culturalmente privilegiadas o desfavorecidas.

\section{La disputa por las consultas populares contra la minería en Colombia}

Las consultas populares están ancladas en la Constitución colombiana de 1991 (arts. 103-106) como mecanismos de participación democrática directa. Su uso está regulado por la Ley nacional de participación (Ley 134 de 1994, arts. 50-57). Además, en relación con las políticas de descentralización de los años noventa, la Ley 136 de 1994 tendiente a organizar y modernizar el funcionamiento de los municipios, otorga a estos una autonomía política amplia y les permite hacer consultas populares sobre proyectos planeados que puedan potencialmente afectar el uso de la tierra y perjudicar el medio ambiente, incluyendo proyectos de minería, explotación de petróleo y gas (art. 33). ${ }^{2}$

Hasta julio de 2015, solo los alcaldes tenían derecho a convocar consultas populares a nivel municipal, pero tras la aprobación de la Ley 1757 de 2015 que busca promover y proteger el derecho a la participación

2 En febrero de 2019, la Corte Constitucional de Colombia en sentencia C-053/19 declaró inválida esta norma legal. Según la decisión de la Corte, los proyectos mineros que podrían potencialmente afectar el uso de la tierra, perjudicar al medio ambiente o la salud humana en una municipalidad determinada no requieren consulta popular previa. 
democrática, “cualquier ciudadano, organización social, partido o movimiento político" están facultados para promover un referendo local por medio de recolección de firmas. Estas consultas populares, independientemente de quien las inicie, deben ser aprobadas por una mayoría simple en el Concejo Municipal. Son legalmente válidas cuando participa al menos el 33 por ciento de los votantes registrados. Los resultados son vinculantes para el Ejecutivo (por ejemplo, un gobierno local) y deben ser implementados a través de un acto administrativo.

La primera consulta popular por explotación minera fue llevada a cabo en Piedras (Tolima) el 28 de julio de 2013. Como parte del proyecto de minería de oro La Colosa, en el municipio de Cajamarca (Tolima), la empresa minera aurífera AngloGold Ashanti (AGA) había planeado construir un depósito para los desechos de aguas tóxicas en Piedras. En la consulta popular del 28 de julio participaron más del 50 por ciento de los votantes registrados y la mayoría votó en contra de las actividades mineras, pero ni el Gobierno nacional ni AGA reconocieron el voto como legítimo o jurídicamente vinculante (Villalba, 2018). Sin embargo, como consecuencia del voto, la empresa cambió los planes del proyecto y decidió localizar todos los aspectos del proceso de extracción (minería, procesamiento y residuos) en Cajamarca (AngloGold Ashanti, 2013).

Medio año después, el 15 de diciembre de 2013, se realizó la primera consulta popular sobre exploración y explotación petrolera en el municipio de Tauramena (Casanare), en la cual participó el 34 por ciento de los votantes registrados. De estos, un 96 por ciento votó en contra del proyecto petrolero. Con la consulta popular en Tauramena - un municipio en donde ya se permitía la explotación minera en grandes áreas-, sus habitantes se opusieron a los planes de la empresa colombiana Ecopetrol con tal de defender el abastecimiento de agua y la valoración de la economía tradicional (Roa García, 2016, pp. 22-24).

Sobre la base del éxito en Piedras y Tauramena, entre el 2014 y el 2016 varios comités del medio ambiente y grupos de protestas de diferentes 
municipios se movilizaron por medio de consultas populares. No obstante, a febrero de 2017, esas movilizaciones habían fracasado, pues, en algunos casos, los alcaldes no apoyaron las iniciativas; en otros, no pasaron el voto del Concejo Municipal; y en otros, las empresas o asociaciones de mineros iniciaron procesos legales para detener el curso de la votación alegando que se estaban violando derechos fundamentales como el derecho al trabajo y a la propiedad privada o cuestionando la constitucionalidad de la pregunta propuesta.

Este último fue el caso de una consulta popular en el municipio de Pijao (Quindío), donde en marzo de 2015 una corte regional prohibió la consulta por la supuesta inconstitucionalidad de la pregunta planteada. En reacción a esta prohibición, una residente de Pijao se opuso legalmente a la decisión argumentando que resultaba directamente afectada por la minería y que la suspensión del voto violaba su derecho a la participación ciudadana. Tras una serie de sentencias, el caso se llevó a la Corte Constitucional, tribunal que en agosto de 2016, en una decisión sin precedentes - la sentencia T-445/16 - dictaminó que las consultas populares por minería eran legales y legítimas. Los jueces afirmaron que los gobiernos locales y regionales estaban autorizados para regular el uso del suelo y garantizar la protección del medio ambiente en sus jurisdicciones por medio de la consulta popular, aunque ello implicara la prohibición de la minería.

La sentencia T-445/16 impulsó aún más a los protagonistas de las consultas populares: entre febrero y octubre de 2017 se llevaron a cabo exitosamente siete consultas por minería y explotación de petróleo a nivel municipal, y en el 2018 se hicieron dos más (ver tabla 1).

Dos de las consultas - las de Cajamarca y Cumaral- sobresalen por el efecto que tuvieron en los proyectos de extracción en cuestión, en la movilización de las consultas populares en el país y en la reacción del Gobierno nacional. El 27 de abril de 2017, un mes después de la votación en Cajamarca, AGA públicamente anunció su retirada temporal de toda actividad minera e inversionista en el municipio. Aunque los 


\section{Tabla 1. Consultas populares por minería/ petróleo en Colombia 2013 - 2018}

\begin{tabular}{|c|c|c|c|}
\hline N. ${ }^{\circ}$ & Municipio/departamento/caso & Fecha de votación & Resultados \\
\hline 1 & $\begin{array}{c}\text { Piedras, Tolima } \\
\text { (Oro, La Colosa; AngloGold } \\
\text { Ashanti) }\end{array}$ & 28 de julio, 2013 & $\begin{array}{l}\text { Participación: } 58.9 \% \\
\text { Contra la minería: } \\
98.8 \%\end{array}$ \\
\hline 2 & $\begin{array}{l}\text { Tauramena, Casanare } \\
\text { (Petróleo, Odisea 3D; } \\
\text { Ecopetrol) }\end{array}$ & 15 de diciembre, 2013 & $\begin{array}{c}\text { Participación: } 34.0 \% \\
\text { Contra la minería: } \\
96 \%\end{array}$ \\
\hline 3 & $\begin{array}{l}\text { Cabrera, Cundinamarca } \\
\text { (Sin proyecto específico) }\end{array}$ & 26 de febrero, 2017 & $\begin{array}{l}\text { Participación: } 43.5 \% \\
\text { Contra la minería: } \\
97 \%\end{array}$ \\
\hline 4 & $\begin{array}{c}\text { Cajamarca, Tolima } \\
\text { (Oro, La Colosa; AngloGold } \\
\text { Ashanti) }\end{array}$ & 26 de marzo, 2017 & $\begin{array}{l}\text { Participación: } 38.6 \% \\
\text { Contra la minería: } \\
\quad 97.92 \%\end{array}$ \\
\hline 5 & $\begin{array}{l}\text { Cumaral, Meta } \\
\text { (Petróleo, Llanos 69; } \\
\text { Mansarovar Energy) }\end{array}$ & 4 de & $\begin{array}{l}\text { Participación: } 48.8 \% \\
\text { Contra la minería: } \\
97 \%\end{array}$ \\
\hline 6 & $\begin{array}{l}\text { Pijao, Quindío } \\
\text { (Metales; sin proyecto } \\
\text { específico) }\end{array}$ & lio, 2017 & $\begin{array}{c}\text { Participación: } \\
44.28 \% \\
\text { Contra la minería: } \\
\quad 97.76 \%\end{array}$ \\
\hline 7 & $\begin{array}{l}\text { Arbeláez, Cundinamarca } \\
\text { (Materiales de construcción; } \\
\text { sin proyecto específico) }\end{array}$ & 9 de julio, 2017 & $\begin{array}{c}\text { Participación: } \\
49.32 \% \\
\text { Contra la minería: } \\
98.5 \%\end{array}$ \\
\hline 8 & $\begin{array}{c}\text { Jesús María, Santander } \\
\text { (Carbón/caliza; sin proyecto } \\
\text { específico) }\end{array}$ & 17 de septiembre, 2017 & $\begin{array}{l}\text { Participación: } 53 \% \\
\text { Contra la minería: } \\
97.1 \%\end{array}$ \\
\hline 9 & $\begin{array}{c}\text { Sucre, Santander } \\
\text { (Carbón/caliza/minerales, } \\
\text { Luciana; Llano Minas) }\end{array}$ & 1 de octubre, 2017 & $\begin{array}{c}\text { Participación: } \\
52.09 \% \\
\text { Contra la minería: } \\
\text { 98.9\% }\end{array}$ \\
\hline 10 & $\begin{array}{c}\text { Fusagasugá, Cundinamarca } \\
\text { (Fracking/minerales; } \\
\text { sin proyecto específico) }\end{array}$ & 21 de octubre, 2018 & $\begin{array}{c}\text { Participación: } 37.6 \% \\
\text { Contra la minería: } \\
99.2 \%\end{array}$ \\
\hline 11 & $\begin{array}{l}\text { San Lorenzo, }{ }^{1} \text { Nariño } \\
\text { (Oro, Mazamorras Gold; } \\
\text { Gran Colombia Gold) } \\
{ }^{1} \text { Consulta autónoma. }\end{array}$ & 25 de noviembre, 2018 & $\begin{array}{l}\text { Participación: } 53.5 \% \\
\text { Contra la minería: } \\
98.5 \%\end{array}$ \\
\hline
\end{tabular}


reclamos de los protagonistas por la cancelación de todas las concesiones mineras existentes en Cajamarca hasta el momento de este escrito no han sido cumplidos aún por el Gobierno nacional, con la suspensión inmediata de las actividades de explotación de AGA este municipio se convirtió en el punto de referencia para otras consultas en todo el país.

Tanto la votación en Cajamarca como, definitivamente, la consulta en Cumaral (Meta) en junio de 2017, cuando el pueblo votó sobre la exploración y explotación de petróleo - la columna vertebral de los ingresos públicos del Estado- han provocado un debate encendido a nivel nacional sobre la legalidad, legitimidad y alcance de las consultas populares. El Ministerio de Minas y Energía anunció un proyecto de ley para regular el uso de las consultas populares como mecanismo para prohibir la ejecución de desarrollos petroleros y mineros, pero al final este nunca ha sido presentado (Reuters, 2017).

Para llamar la atención sobre el asunto, los senadores del Polo Democrático Alternativo realizaron en dicha cámara un debate sobre la consulta popular, el 26 de septiembre de 2017, en el cual participaron los activistas del movimiento, el Ministerio de Minas y Energía y la Agencia Nacional de Minería. Además, y como reacción inmediata, en octubre de 2017 el Gobierno detuvo la financiación de consultas por medio del Consejo Nacional Electoral. Esta entidad, precisamente, debido al incremento de las consultas, había aplicado para obtener un presupuesto más grande, solicitud que fue rechazada por el Ministerio de Hacienda. Como resultado, hacia finales de 2017, seis referendos sobre minería y explotación de petróleo que habían sido ya planeados y estaban próximos a realizarse fueron cancelados. ${ }^{3}$ (El Tiempo, 2017a; El Espectador, 2017a).

Al comienzo del 2018, al menos 54 consultas populares estaban en trámite (El Tiempo, 2018b), pero al finalizar el año la mayoría quedó

3 https://www.land-conflicts.fu-berlin.de/multimedia/uebersicht-consultas/index. html, consultado por última vez el 12 de noviembre de 2018. 
en un limbo jurídico y político. Las causas de esto varían entre falta de presupuesto, un incremento en las amenazas de paramilitares contra los comités locales que las organizan, ${ }^{4}$ una serie de procesos legales y un cambio jurídico en la disputa. Antes de la consulta popular en Cumaral, la compañía afectada, Mansarovar Energy Colombia, cuestionó la constitucionalidad de este mecanismo de participación en una corte administrativa nacional, aunque no tuvo éxito. Empero, en agosto de 2017, la Corte Constitucional revisó el caso e invitó a representantes de la empresa, la sociedad civil, el Gobierno nacional y local, la corte regional, asociaciones empresariales y organismos de control a una audiencia pública que se realizó el 12 de abril de 2018 en Bogotá.

Seis meses después, el 11 de octubre de 2018, la Corte anunció en el Comunicado N. ${ }^{\circ} 40$ una decisión histórica. Sostuvo en dicho comunicado que, como los recursos del subsuelo le pertenecen al Estado nación, los gobiernos locales no tienen jurisdicción para decidir sobre su uso mediante una consulta popular. Esto implica "que este mecanismo de participación ciudadana no puede ser utilizado para prohibir actividades de extracción en un determinado municipio o distrito” (párr. 8). No obstante, la Corte también reconoció que el sistema político carece de mecanismos adecuados para la participación democrática y para la coordinación y acuerdos entre los niveles nacional, departamental y local respecto a la extracción de recursos. Por tal razón, pidió al

4 Un ejemplo concreto es el Comité Local del Medio Ambiente de Roncesvalles, una municipalidad del departamento del Tolima. En septiembre de 2018, los miembros de la comunidad recibieron amenazas de una organización paramilitar conocida, para que detuvieran todas las actividades relacionadas con la movilización por la consulta popular contra proyectos mineros y de hidroenergía en la municipalidad. Como respuesta, y por razones de seguridad, el comité declaró el cese de todas sus actividades públicamente (Alerta Tolima, 2018). Además, las amenazas y ataques contra líderes sociales, particularmente aquellos involucrados en protestas contra las actividades de extracción, han incrementado en Colombia a nivel nacional. Estudios recientes enumeran más de 400 activistas sociales asesinados entre el 2016 y el 2018; muchos vivían en áreas rurales y eran activos en grupos de acción comunitaria u organizaciones por el medio ambiente (González Posso, 2018; Somos Defensores, 2018; ver también http://www.defensoria.gov.co/, consultado por última vez el 1 marzo de 2019). 
Congreso definir en el menor tiempo posible "uno o varios mecanismos de participación ciudadana y uno o varios instrumentos de coordinación y concurrencia nación-territorio” (párr. 10), de acuerdo con los criterios constitucionales que allí mismo determinó.

Mientras tanto, las ONG, organizaciones del movimiento en contra de la minería, académicos y gobiernos locales anunciaron su oposición a la decisión (entrevista a abogado independiente experto en derecho ambiental, 25 de septiembre de 2018; El Tiempo, 2018a). Asimismo, a pesar de la decisión de la Corte Constitucional, se llevaron a cabo consultas populares exitosas el 21 de octubre de 2018 en Fusagasugá (Cundinamarca) y el 25 de noviembre de 2018 en San Lorenzo (Nariño). Esta última no fue apoyada por el Consejo Nacional Electoral y, por lo tanto, debe ser considerada como una consulta autónoma que, sin embargo, movilizó a más de la mitad de los votantes registrados de la localidad.

\section{Contrarrestando reclamos por participación democrática popular - las narrativas}

En sus protestas, los actores de movimientos de la sociedad civil y del Estado local utilizan narrativas de democracia y autonomía territorial para legitimar la organización de consultas populares y para cuestionar las relaciones de poder que forman la base de la política de recursos en Colombia. La consulta popular es presentada como un mecanismo legítimo de participación democrática reconocido constitucionalmente (entrevista presidente del Concejo Municipal de Ibagué, 8 de octubre de 2016; El Tiempo, 2017c). Para justificar acciones y obtener apoyo público, los protagonistas usan historias ampliamente reconocidas sobre la soberanía del pueblo como un elemento central de la democracia. Un miembro del Concejo Municipal de Piedras, por ejemplo, relató la decisión de organizar una consulta popular de la siguiente manera: "Hemos iniciado la consulta basándonos en la soberanía del pueblo colombiano, un poder que le pertenece solo al pueblo" (discusión en grupo, Piedras, 4 de septiembre de 2015). Otros utilizan historias sobre el derecho de 
autodeterminación y una transición democrática muy necesaria para reclamar un cambio en la política nacional de recursos:

Creemos que es esencial que las comunidades sean parte integral de las dinámicas de sus propias vidas. (...) ¿Por qué no nos consultan? ¿Por qué no nos preguntan? (...) Tiene que haber una transición desde la democracia representativa hacia la democracia participativa. Es un mandato constitucional. (Entrevista a protagonista de la consulta popular, Ibagué, 7 de octubre de 2016).

¿Cómo están siendo contrarrestadas estas narrativas y reclamos por la falta participación democrática popular y por la transformación de las relaciones de poder en el sector de recursos mineroenergéticos entre el Estado nacional y local, por los actores del Estado nacional y de las corporaciones? Entre los datos de análisis, he identificado cuatro narrativas principales que los antagonistas de las consultas populares han aplicado en la disputa: la narrativa de legalidad y legitimidad, la narrativa de ideología y desinformación, la narrativa de participación y la narrativa de desarrollo.

\subsection{La narrativa de legalidad y legitimidad}

Al comienzo de la disputa, las consultas populares fueron representadas por actores corporativos y del Estado nacional como ilegales. Una historia frecuentemente repetida era que, con la organización de consultas populares contra la minería, el Gobierno local y los grupos de protesta estaban transgrediendo su jurisdicción e invalidando la del Gobierno nacional. El punto crítico aquí está relacionado con el asunto en cuestión - la extracción de recursos del subsuelo- y la distribución de la jurisdicción dentro del Estado. Las consultas populares locales son concebidas como un instrumento que puede ser aplicado a los asuntos locales, pero no a la minería o explotación de petróleo, ya que estas actividades son reguladas por el Estado nacional (entrevista a viceministro de Minas y Energía, 21 de septiembre de 2015). De acuerdo con 
esta historia, el día después de la votación en Piedras, el oficial de comunicaciones de AGA afirmó: "Es el Gobierno Nacional el único que puede definir y decidir sobre el mejor uso que debe dársele a la riqueza del subsuelo" (El Tiempo, 2013a). Las empresas y actores del Estado basaron sus reclamos en el Decreto 934 del 9 de mayo de 2013, cuyo primer artículo declara que excluir actividades mineras de las áreas del territorio nacional es jurisdicción únicamente del Gobierno nacional.

La narrativa de la ilegalidad de las consultas populares va de la mano de la historia de la legitimidad de la toma directa de decisiones democráticas respecto a la extracción de recursos. Esta última es narrada en términos de una oposición binaria simple: intereses locales particulares versus interés común, o, en otras palabras, pocos contra muchos. Se planteó la pregunta de si era buena idea dejar a los ciudadanos locales de una municipalidad decidir sobre el desarrollo de un proyecto que tendría intereses nacionales generales (entrevista a funcionario AGA, 31 de octubre de 2016; Bonilla Mora, 2018); al respecto, en la audiencia pública en la Corte Constitucional ya referida, el vicepresidente jurídico de Ecopetrol enfatizó que el problema generado por las consultas era el predominio de los intereses particulares de una entidad subnacional sobre los intereses del Estado, los cuales representan los intereses de todos (AP, 2:04:35-2:08:08).

De la misma manera, en una reunión en la sede de Ecopetrol, financiada por el Ministerio de Minas y Energía para convencer a autoridades del municipio de Tauramena de la inconveniencia de la consulta, el ministro de Minas 2013-2014, Amilkar Acosta, argumentó que la consulta popular es "una medida extrema" innecesaria y la "última carta que una comunidad (...) puede jugar” (citado por Roa García, 2016, p. 26). Para dar más poder a esta narrativa, el ministro y viceministro de Minas presentaron las consultas populares como una amenaza al Estado de derecho y a la democracia representativa. En este sentido, en una entrevista para los medios después de la votación en Cajamarca, el ministro de Minas, Germán Arce, afirmó que unas personas que votan contra de 
la minería pueden quizás influenciar las acciones de su alcalde, pero "no tienen la capacidad de romper el Estado Social de Derecho" ( $E l$ Espectador, 2017b). En septiembre de 2017, el viceministro añadió que la democracia representativa no puede ser sustituida por la democracia directa, donde todas las decisiones políticas pasan por un referendo local o regional (Carlos Cante, DS, 31:14-34:22).

Otra estrategia para deslegitimar el voto popular contra la minería fue el cuestionamiento público de su naturaleza vinculante y del alcance temporal de sus resultados. Mientras que los abogados de derechos humanos y del medio ambiente subrayan repetidas veces que las consultas populares son mecanismos de participación democrática directa y vinculante, y que su cumplimiento legal es obligatorio, el viceministro de Minas, Carlos Cante, recalca que no hay claridad respecto a la naturaleza vinculante de las consultas populares (Arenas, 2017; entrevista a abogado de derechos humanos, Bogotá, 10 de abril de 2017). Posteriormente, el ministro de Minas puso en duda sus efectos retroactivos, arguyendo que una consulta local no podía contrarrestar una decisión tomada previamente por la administración del Estado nacional. El mensaje enviado era claro: la consulta popular no tendría efecto sobre proyectos existentes donde han sido ya otorgadas concesiones mineras (El Espectador, 2017b).

\subsection{La narrativa de ideología y desinformación}

Adicionalmente, la consulta popular fue acusada de estar cargada emocional e ideológicamente y de ser aprovechada por sus promotores para fines políticos, más allá de una simple oposición a la minería. Una de las historias principales era que los organizadores de las consultas las utilizaban para sus campañas políticas, por ejemplo, para obtener el apoyo de un partido o movimiento político particular en elecciones de alcaldes o para sus aspiraciones políticas individuales. Según esta narrativa, aquellos que se movilizaron a favor de las consultas populares son sospechosos de tener vínculos directos con organizaciones guerrilleras de izquierda (Rueda, 2017). 
Otra narrativa se centraba en los argumentos "falsos” utilizados por los organizadores de las consultas populares durante el proceso de movilización. El ministro de Minas, Germán Arce, descalificó las consultas diciendo que sus promotores jugaban con las emociones del pueblo oponiendo el "petróleo versus agua” (El Espectador, 2017c). En vez de informar al pueblo con datos técnicos comprobados y argumentos razonables, los organizadores fueron acusados de difundir desinformación, de añadir carga emocional a datos complejos, y de manipular y causar confusión entre el electorado local al no decirle la verdad (entrevista por correo electrónico, funcionario AGA, 16 de noviembre de 2016).

\subsection{La narrativa de participación}

Tras la sentencia T-445/16 de la Corte Constitucional, expedida el 19 agosto de 2016, surgió una nueva narrativa sobre "derecho a la participación”, pues en esta la Corte confirmó el fundamento constitucional de las consultas populares contra la extracción de recursos, particularmente en casos donde se anticiparan efectos medioambientales y socioeconómicos adversos. Como reacción, los antagonistas comenzaron a contrarrestar los reclamos por participación democrática y control autónomo territorial sobre los recursos ajustando sus historias a esos reclamos.

La consulta popular se comienza a considerar, entonces, un mecanismo de participación democrática legítimo que se debe respetar. Así, el problema principal dejó de ser el reclamo por la participación democrática en sí y empezó a serlo la percibida falta de aplicación de mecanismos constitucionales de coordinación, concurrencia y subsidiariedad entre los diferentes niveles del Estado (Carlos Cante, viceministro de Minas, DS, 5:29-34:22; Silvana Habid, presidente de la ANM, AP, 1:55:00-1:55:35).

Una narrativa frecuente se refería a la necesidad de tener un "diálogo informado entre iguales”. En este sentido, tras retirarse de Cajamarca en abril de 2017, AGA subrayó que continuaría trabajando en la búsqueda del diálogo constructivo y sincero con las comunidades locales, ya que 
estas constituían parte fundamental del proceso (El Tiempo, 2017d). El Ministerio de Minas y Energía, la ANM, la ANH y las asociaciones corporativas expresaron en varias ocasiones, particularmente en los debates del Senado y durante la audiencia pública en la Corte Constitucional, que lo necesario era escuchar al pueblo, cumplir sus reclamos de participación, crear relaciones con el territorio desde el principio, implementar mecanismos eficientes de participación informada, iniciar diálogos, trabajar en conjunto por un objetivo en común y contribuir en adelante con la construcción de paz en el territorio (Carlos Cante, viceministro, DS, 5:29-34:22; Orlando Velandia Sepúlveda, presidente de la ANH, AP, 1:38:00-1:41:00).

Paralelamente, la ANH y la ANM, junto con el Ministerio de Minas y Energía, intensificaron los esfuerzos por implementar mecanismos alternativos de consulta y diálogo con comunidades y administraciones locales, apuntando a "evitar consultas populares" (entrevista a funcionario del MME, 21 de marzo de 2017). Con un programa llamado Estrategia Territorial para la Gestión Equitativa y Sostenible del Sector Hidrocarburos, la ANH había iniciado desde el 2013 un programa de consultas que se debía llevar a cabo antes de cada explotación de petróleo en un territorio determinado. La ANM, por su parte, comenzó un programa similar en el 2016 mediante la realización de lo que denominaron "audiencias públicas”. Según la página web de la entidad, hasta marzo del 2019 las habían realizado en 54 municipios. ${ }^{5}$ Dichas audiencias se hacen en la fase de preotorgamiento de un título de minería y consisten, principalmente, en explicar el proceso del proyecto minero y presentar propuestas en contra de este. Cuentan también con la participación de las empresas que proponen el proyecto, para las cuales este resulta ser un escenario muy importante, ya que ahí pueden capturar el espíritu de una comunidad y darse cuenta si la población es abierta $u$ hostil frente al proyecto minero que presentan. Además, el encuentro con la comunidad

5 https://www.anm.gov.co/?q = audiencias_publicas_principal, consultado por última vez el 4 de abril de 2019 . 
les permite identificar los sectores donde deben invertir para recibir la licencia social.

Es importante recalcar que en este espacio la población puede dar a conocer sus preocupaciones y hacer preguntas, pero no tiene poder de decisión; lo que significa que no puede prohibir el proyecto (entrevista con miembros del Programa de Relacionamiento con el Territorio, de la ANM, 27 de marzo de 2019). Sin embargo, con este "mecanismo de participación eficiente e informado", conocido como "construcción colectiva del territorio”, la Agencia dice estar aplicando una "buena práctica colectiva" (Silvana Habib, presidente de la ANM, DS, 45:20-52:15; AP, 1:50:30-1:54:10).

\subsection{La narrativa de desarrollo}

Después de las consultas en Cajamarca y otros municipios en 2017, emergió otra narrativa: la de desarrollo. En su declaración inicial en la audiencia pública de la Corte Constitucional, el ministro de Minas subrayó la importancia del sector minero y de hidrocarburos para la economía nacional. Sostuvo que el 25 por ciento de las finanzas públicas nacionales salen del sector, que la mitad de la inversión extranjera directa está orientada hacia él y que gracias a los ingresos que se obtienen del sector ha sido posible financiar grandes proyectos de desarrollo en el país como, por ejemplo, la construcción de carreteras, educación, energía y salud (Germán Arce, ministro de Minas, AP, 1:07:42-1:14:40). Desde este punto de vista, la consulta popular representa una amenaza a la inversión, a los ingresos nacionales, a las ganancias corporativas y, finalmente, al control sobre el sector.

Surgió así una historia evidente dentro de esta narrativa: la oposición "desarrollo versus pobreza”. En una entrevista a los medios, Francisco José Lloreda, exministro de Desarrollo y actual director de la Asociación Colombiana del Petróleo, calificó la consulta popular como una grave amenaza al desarrollo y la calidad de vida: "el dilema no es entre agua y petróleo, el dilema es 
si nosotros queremos más desarrollo o más pobreza; si queremos más impuestos o menos impuestos" (Rueda, 2017). Para que esta narrativa sea más poderosa, se han aplicado además cálculos y estadísticas demostrando los millones de pesos colombianos que el Estado ha perdido en sus ingresos a causa del voto popular; dinero que no se pudo invertir en los sectores salud y educación (El Tiempo, 2017b).

El mensaje principal de esta narrativa moralizadora es que "no hay otra alternativa” distinta de la minería y explotación de petróleo, porque de otra manera la "educación gratuita, cobertura universal de salud, ayuda a los más pobres y pensiones para los ancianos” no podrían ser costeados y no habría suficiente trabajo en el país (El Tiempo, 2017b, 2018c). Adicionalmente, los antagonistas han recalcado que las consultas son un desperdicio de fondos públicos que se podrían emplear mejor en proyectos de desarrollo (entrevista a funcionario de MME, Bogotá, 21 de marzo de 2107). De este modo, los antagonistas acusan a los gobiernos locales y a las organizaciones sociales que se han movilizado en referendos municipales de ser responsables de que las comunidades rurales no estén conectadas a la red eléctrica o de que no tengan una escuela o centro médico decente. Más aún, a los alcaldes que apoyan la consulta popular en su jurisdicción los acusan de recibir fondos del Gobierno nacional derivados de los ingresos por recursos mineros y al mismo tiempo estar prohibiendo las actividades que producen dichos ingresos (Carlos Cante, viceministro Minas y Energía, DS, 26:22-28:34).

\section{Surgimiento, transformación y poder de las narrativas}

En la disputa por la consulta popular, las historias contadas por antagonistas se multiplicaron y cambiaron a través del tiempo como resultado del intercambio social y el cambio en las condiciones contextuales. Tres eventos claves dieron origen a las diferentes narrativas empleadas por los actores del Estado y corporativos: la primera consulta popular, en Piedras, en julio de 2013; la sentencia T-445/16 de la Corte Constitucional 
en agosto de 2016; y la ola de consultas populares del 2017, que fue impulsada por la consulta exitosa en Cajamarca, en marzo de ese año.

Al comienzo de la disputa prevalecieron las narrativas que ayudaron a deslegitimar e ilegalizar las consultas populares, y a difamar y criminalizar a los protagonistas. Estas narrativas correspondieron con las acciones asumidas por el Gobierno nacional para detener las consultas y neutralizar los reclamos de participación democrática durante el periodo 2013-2018, tales como represión, intervenciones legales y persecución de los actores estatales y no estatales que promocionaban las consultas populares. Estas narrativas siguen siendo significativas hoy; sin embargo, han emergido nuevas narrativas en el transcurso del conflicto y en relación con los eventos claves que han cambiado el curso de la disputa.

Una ruptura crucial en las narrativas con las que los antagonistas dieron significado a las consultas populares fue producida por la sentencia T-445/16, que alteró la selectividad discursiva del contexto. Para contrarrestar los reclamos de los actores del movimiento ambientalista y del Estado local, que fueron reforzados por la sentencia de la Corte antes mencionada, los antagonistas adaptaron sus historias a los reclamos de los actores sociales, como se puede verificar en el surgimiento de la narrativa de participación. En esta narrativa, una variedad de nociones centrales como "construcción colectiva del territorio", "prácticas colectivas” y el "derecho a la participación” fueron extraídas de los protagonistas y (re)interpretadas con el objetivo de neutralizar su significado simultáneo y continuar reproduciendo las relaciones de poder existentes. Por lo tanto, desde el 2016 el derecho a la participación democrática ha sido discursivamente reconocido.

Las acciones lideradas por la administración nacional que corresponden con esta estrategia discursiva abarcan la introducción de procesos participativos y programas de consultas antes de otorgar concesiones. Con estas estrategias, los reclamos de participación democrática y autodeterminación territorial son gradual y parcialmente asumidos en el 
sistema de regulación existente. Empero, estos nuevos mecanismos no proveen a la población ni a los actores del Estado local una voz institucionalmente reconocida en la toma de decisiones sobre la extracción de recursos y, por tanto, no ha ocurrido un cambio institucional fundamental en el sector minero energético.

Una segunda fractura en las narrativas de los antagonistas fue ocasionada por la ola de consultas populares sobre minería y explotación de petróleo ocurridas en el 2017. Este incremento acelerado de consultas populares demuestra una crisis política dentro del sector en Colombia que puso al Gobierno en alerta. Según un miembro de una organización de derechos humanos, la ola de consultas reflejó el incremento de acción política por parte de la sociedad: "Las consultas populares representan un cambio en la política colombiana de minería. Son el mayor golpe para esa política y su mensaje al Gobierno es claro: ¡Aquí estamos!” (entrevista, Bogotá, 27 de octubre de 2017). Un abogado de derecho ambiental confirmó esta misma percepción: "La consulta popular es como el despertar de la democracia. Con la consulta popular, emergió un proceso de democratización en las relaciones entre el Estado y la sociedad” (entrevista, Bogotá, 27 de octubre de 2017). Además, un funcionario del Ministerio de Minas y Energía reconoció que ha fallado la política del sector en su relación con la sociedad (entrevista, Bogotá, 21 de marzo 2017).

Finalmente, la declaración de AngloGold Ashanti al anunciar el cese de actividades en Cajamarca comprueba que la compañía percibió inestabilidad político-económica e institucional en el sector colombiano de los recursos:

Diversas razones que van desde lo institucional, lo político, y particularmente lo social con la reciente consulta, nos obligan a tomar la desafortunada decisión de detener todas las actividades en el proyecto (...) mientras se le da certeza a la actividad minera en el país y en Tolima. (2018, párr. 3). 
Es por esta razón que, desde el 2017, ha sido necesaria una narrativa más poderosa capaz de contrarrestar los reclamos de los actores de la protesta y restaurar las relaciones de poder y estabilidad dentro del sector, por lo que emergió la narrativa de desarrollo. La importancia de esta narrativa resultó particularmente evidente en la audiencia pública de la Corte Constitucional del 2018, donde las intervenciones de todos los actores del Estado y las corporaciones estaban permeadas por historias relacionadas con la importancia económica de la extracción de recursos para la económica nacional y local; intereses públicos (nacionales) versus particulares (locales); y la distribución de la jurisdicción y el poder entre el Estado nacional y local sobre la regulación de los recursos del subsuelo y la promoción de los procesos de desarrollo. Una estrategia que correspondió con esta narrativa fue la de retirar la financiación de las consultas populares.

Aunque las cuatro narrativas parecen existir aisladas y paralelamente, en realidad están entrelazadas de muchas maneras y con frecuencia se emplean en combinación. Las narrativas despliegan poder cuando están bien adaptadas a los escenarios y públicos donde son relatadas. Con las cuatro narrativas, los antagonistas han desarrollado un poderoso repertorio discursivo para contrarrestar los reclamos de los actores del movimiento no solo en un escenario, sino en varios diferentes.

La narrativa de legalidad y legitimidad es con frecuencia empleada estratégicamente en conexión con la narrativa de ideología y desinformación, en entrevistas en periódicos y otros medios de comunicación. El destinatario aquí es el público en general, que en Colombia está ideológicamente polarizado y es susceptible a mensajes e historias enfrentadas. En contraste, las narrativas de participación y desarrollo con frecuencia se escuchan en conjunto en escenarios institucionales, políticos y formales como la Corte Constitucional o el Congreso de la República (Senado o Cámara de Representantes). En ellos el público se compone mayoritariamente de jueces y parlamentarios; es decir, funcionarios del Estado cuyas normas, valores y creencias culturales son, en la mayoría 
de los casos, consistentes con las nociones ideales del Estado liberal democrático moderno.

Como “protectoras del statu quo", sostiene Polletta (2006), las narrativas adquieren influencia no solo porque algunos actores logran absorber elementos narrativos del otro, sino también porque las narrativas se entretejen con oposiciones familiares basadas en normas y valores culturalmente dominantes y aceptados. A lo largo de la disputa, las historias de los antagonistas fueron entrelazadas con oposiciones culturalmente reconocidas, (re)produciendo el sentido común ideológico que apoya las leyes, políticas y prácticas. Entre las oposiciones recurrentes están lo legal versus lo ilegal, los intereses públicos versus los particulares, la jurisdicción nacional versus la local, lo político versus lo legal, el conocimiento experto y técnico versus el popular, el progreso y desarrollo versus el atraso y la pobreza, y la democracia representativa versus la directa.

Las historias que construyen la consulta popular como una amenaza al Estado de derecho o al desarrollo cobran sentido en el contexto de dichas comparaciones. Estas historias se escuchan en el marco del sentido común ideológico, que establece que el Estado de derecho y el sistema de democracia representativa son los principales logros del Estado moderno y plantea que solo a través de estas instituciones el interés de las masas puede ser garantizado. Desde esta perspectiva, las formas directas o participativas de procesos de decisión democrática son un riesgo para la estabilidad institucional del Estado moderno, y el bienestar y el desarrollo social dependen del crecimiento económico, la inversión extranjera directa, la prosperidad corporativa y, finalmente, de la extracción de los recursos.

\section{Conclusión}

Este análisis sobre la disputa por la jurisdicción en el sector de recursos minero energéticos en Colombia ha demostrado que los actores del 
Estado nacional que hacen parte de la administración de la minería e hidrocarburos, junto con los aliados corporativos, aplican una variedad de estrategias enlazadas entre sí como contraprotesta a los reclamos de actores sociales y del Estado local por la institucionalización de la participación democrática. Dichas estrategias van desde la represión, criminalización, judicialización y vaciamiento financiero hasta la integración parcial.

Para que estas estrategias restrinjan efectivamente los reclamos de los actores de protesta, y para lograr que el público las respalde y apoye, se relatan diferentes historias. Así, con el objetivo de reproducir las relaciones de poder existentes en el sector de los recursos minero energéticos, los actores estatales y sus aliados conectan cuatro narrativas diferentes y varias historias fundamentales: la narrativa de legalidad y legitimidad, la narrativa de ideología y desinformación, la narrativa de participación y la narrativa de desarrollo. De esta manera, se crea un repertorio de narrativas que, dependiendo del escenario, el público y el contexto, son aplicadas alternativa o complementariamente para señalar exitosamente que las consultas populares se deben detener.

Las narrativas no son fijas sino dinámicas; tampoco tienen significado fuera de las acciones llevadas a cabo por los antagonistas de las consultas populares. La narrativa de participación, por ejemplo, así como la historia de promulgar un diálogo entre iguales, solo tienen sentido o fiabilidad en relación con la implementación de mecanismos de participación en el mencionado sector. Por otra parte, las narrativas utilizadas no emergen aisladamente; al contrario, se desarrollan y cambian en interacción con los actores de oposición y en relación cercana con las condiciones cambiantes del contexto.

Para hacerse escuchar y obtener apoyo del público y de otras entidades estatales, las narrativas que intentan reproducir y estabilizar el statu quo deben ser ajustadas al espíritu del momento, de lo contrario pierden poder. Con la narrativa de participación, por ejemplo, el Gobierno nacional reacciona ante el reclamo legalmente reconocido de 
participación democrática. Por otra parte, la narrativa de desarrollo es una reacción tanto a la crisis económica emergente como a la presión de las compañías transnacionales que amenazan con retirar su inversión en Colombia o con demandar al Estado por compensación de sus pérdidas. En este mismo sentido, tanto la narrativa de legalidad y legitimidad como la de ideología y desinformación continúan siendo importantes, ya que reaccionan contra lo que se percibe como una amenaza a las estructuras político-institucionales del Estado colombiano.

Todo esto no significa que las protestas y los conflictos sociales desaparezcan del todo cuando los actores estatales aplican un conjunto de narrativas. Sin embargo, puede significar una mayor dificultad a futuro para los actores de protestas que buscan el interés y apoyo del público y retar el sentido común ideológico que respalda la decisión de la Corte Constitucional y de las políticas de recursos del Gobierno nacional.

\section{Referencias}

Abbott, Porter. (2008). The Cambridge Introduction to Narrative. Cambridge: Cambridge University Press.

Alerta Tolima. (23 de septiembre de 2018). Ambientalistas en Roncesvalles denuncian amenazas de muerte en su contra. Alerta Tolima. https://alertatolima.rcnradio.com/ambientalistas-en-roncesvalles-denuncian-amenazasde-muerte-en-su-contra/ Recuperado el 19 de diciembre de 2018).

AngloGold Ashanti (Colombia). (Junio 27 de 2013). La Colosa, una oportunidad de oro para el Tolima. https://www.anglogoldashanticolombia.com/ la-colosa-una-oportunidad-oro-tolima/2588/

AngloGold Ashanti (Colombia). (Abril, 2017). Comunicado oficial sobre La Colosa. https://www.anglogoldashanticolombia.com/comunicado-oficial-lacolosa/1719/

Arenas, Fabio. (25 de marzo de 2017). Consulta popular en Cajamarca, clave para el futuro de la minería. El Tiempo. http://www.eltiempo.com/colombia/otras-ciudades/consulta-minera-en-cajamarca-se-realizara-este-domingo-70960. Recuperado el 16 de agosto de 2018. 
Arenas, Natalia. (13 de febrero de 2015). Hoy: el día D del oro. La silla vacía. http://lasillavacia.com/historia/hoy-el-dia-d-del-oro-49576. Recuperado el 28 de septiembre de 2015 .

Asamblea Nacional Constituyente. (1991). Constitución Política de Colombia. Gaceta Constitucional N. ${ }^{\circ} 116$ del 20 de julio de 1991.

Bonilla Mora, Alejandra. (11 de abril de 2018). Consultas y minería, en manos de la Corte Constitucional. El Espectador. https://www.elespectador.com/ noticias/judicial/consultas-y-mineria-en-manos-de-la-corte-constitucionalarticulo-749510. Recuperado el 16 de agosto de 2018.

Christel, Lucas. (2013). Incidencia de las resistencias sociales en las legislaciones mineras provinciales. Los casos de Córdoba y Catamarca (2003-2008). Letras Verdes. Revista Latinoamericana de Estudios Socioambientales, (14), 5-26.

Congreso de Colombia. (1994a). Ley 134 de 1994. Diario Oficial 41.373 del 31 mayo de 1994.

Congreso de Colombia. (1994b). Ley 136 de 1994. Diario Oficial 41377 del 2 de Junio de 1994.

Congreso de Colombia. (2015). Ley Estatutaria 1757 de 2015. Diario Oficial 49.565 del 6 de julio de 2015 .

Corte Constitucional de Colombia. (2018). Comunicado N. ${ }^{\circ} 40$ de octubre 11 de 2018 (Vicepresidenta: Gloria Stella Ortiz Delgado).

Corte Constitucional de Colombia. Sala Sexta de Revisión. Sentencia T-445 de 2016 (M. P.: Jorge Iván Palacio Palacio: agosto 19 de 2016).

Cuevas Guarnizo, Angélica María. (25 de agosto de 2014). Hace un año Piedras le dijo no a la minería: ¿de qué sirvió? El Espectador. https://www.elespectador.com/noticias/nacional/hace-un-ano-piedras-le-dijo-no-mineria-desirvio-articulo-512776. Recuperado el 16 de agosto de 2018.

Delamata, Gabriela. (2013). Actualizando el derecho al ambiente. Movilización social, activismo legal y derecho constitucional al ambiente de «sustentabilidad fuerte» en el sector extractivista megaminero. Revista Entramados y Perspectivas de la Carrera de Sociología, 3(3), 55-90.

Dietz, Kristina. (2018). Direct democracy in mining conflicts in Latin America: mobilising against the La Colosa project in Colombia. Canadian Journal of Development Studies /Revue canadienne d'études du développement. https://doi.org/10.1080/02255189.2018.1467830 
El Espectador. (2017a). ¿Asfixiar las consultas populares? El Espectador, 30 de noviembre, 2017. https://www.elespectador.com/opinion/editorial/asfixiar-las-consultas-populares-articulo-725992. Recuperado el 16 de agosto de 2018.

El Espectador. (2017b). "Consulta minera en Cajamarca no tiene la capacidad de cambiar la ley”: Gobierno. El Espectador, 27 de marzo, 2017. https://www. elespectador.com/noticias/nacional/consulta-minera-en-cajamarca-no-tiene-la-capacidad-de-cambiar-la-ley-gobierno-articulo-686515. Recuperado el 16 de agosto de 2018).

El Espectador. (2017c). Minminas quiere modificar consultas populares. El Espectador, 12 de mayo, 2017. https://www.elespectador.com/noticias/ medio-ambiente/minminas-quiere-modificar-consultas-populares-articulo-693492. Recuperado el 20 de diciembre de 2018.

El Espectador. (2019). Proyectos mineros podrán hacerse sin consultas populares previas. El Espectador, 13 de febrero, 2019. https://www.elespectador. $\mathrm{com} /$ noticias/judicial/proyectos-mineros-podran-hacerse-sin-consultas-populares-previas-articulo-839471. Recuperado el 1 de marzo de 2019.

El Tiempo. (2013a). Estudian validez de consulta que veta minería en Piedras (Tolima). El Tiempo, 29 de julio, 2013. https://www.eltiempo.com/archivo/documento/CMS-12955288. Recuperado el 13 de julio de 2017.

El Tiempo. (2013b). Gremios no aceptan la consulta de Piedras en proyecto. El Tiempo, 30 de julio, 2013. https://www.eltiempo.com/archivo/documento/DR-99920. Recuperado el 13 de julio de 2017.

El Tiempo. (2017a). El Gobierno no financiará más consultas mineras ni revocatorias. El Tiempo, 19 de octubre, 2017. http://www.eltiempo.com/economia/sectores/registraduria-dice-que-las-regiones-deben-financiar-suspropias-consultas-142580. Recuperado el 16 de agosto de 2018.

El Tiempo. (2017b). Por el no a la minería no se recibieron $\$ 226.000$ millones de regalías. El Tiempo, 31 de diceimbre, 2017. http://www.eltiempo.com/ justicia/investigacion/el-pais-dejo-de-recibir-regalias-por-226-000-millonespor-el-no-a-la-mineria-166654. Recuperado el 16 de agosto de 2018.

El Tiempo. (2017c). ¿Por qué se promueven consultas de proyectos mineros y energéticos? El Tiempo, 16 de mayo, 2017. https://www.eltiempo.com/bogota/razones-por-las-que-cundinamarca-ha-convocado-a-votaciones-sobretema-de-mineria-88448. Recuperado el 16 de agosto de 2018. 
El Tiempo. (2017d). Sin extraer un gramo de oro, el proyecto La Colosa frena en seco. El Tiempo, 28 de abril, 2017. http://www.eltiempo.com/economia/ sectores/consecuencias-de-la-detencion-de-produccion-de-la-colosa-82532. Recuperado el 17 de agosto de 2018.

El Tiempo. (2018a). "Ahora el gobierno y las empresas van a pretender imponer su agenda”. El Tiempo, 12 de octubre, 2018. https://www.eltiempo.com/vida/ medio-ambiente/ambientalistas-preocupados-frente-a-decision-de-la-cortesobre-consultas-populares-280190. Recuperado el 12 de octubre de 2018.

El Tiempo. (2018b). El año arranca con 54 consultas pendientes contra minas y energía. El Tiempo, 17 de enero, 2018. http://www.eltiempo.com/ economia/sectores/consultas-mineras-pendientes-contra-minas-y-energia-172302. Recuperado el 12 de marzo de 2018.

El Tiempo. (2018c). "Hay que volver a la concertación entre Nación y regiones”. El Tiempo, 11 de abril, 2018. http://www.eltiempo.com/justicia/cortes/ entrevista-a-luis-guillermo-velez-sobre-consultas-populares-204032. Recuperado el 12 de abril de 2018 .

Ewick, Patricia y Silbey, Susan. (1995). Subversive Stories and Hegemonic Tales: Toward a Sociology of Narrative. Law \& Society Review, 29(2), 197-226. Doi: $10.2307 / 3054010$.

Haarstad, Håvard y Fløysand Arnt. (2007). Globalization and the power of rescaled narratives: A case of opposition to mining in Tambogrande, Perú. Political Geography, 26(3), 289-308.

Hajer, Maarten. (1997). The Politics of Environmental Discourse: Ecological Modernization and the Policy Process. Oxford: Oxford University Press.

Hay, Colin. (2001). What Place for Ideas in the Structure-Agency Debate? Globalisation as a 'Process Without a Subject'. http://www.criticalrealism.com/ archive/cshay_wpisad.html. Recuperado el 13 de agosto de 2018.

Hoetmer, Raphael. (2010). “Esta democracia, ya no es democracia...”. Reflexiones a propósito de la consulta vecinal sobre la minería en la frontera norte del Perú. Yuyaykusun, (3), 183-208.

Moezzi, Mithra; Janda, Kathryn y Rotmann, Sea. (2017). Using stories, narratives, and storytelling in energy and climate change research. Energy Research \& Social Science, 31, 1-10. https://doi.org/10.1016/j.erss.2017.06.034 
Neira, Armando. (4 de junio de 2017). Lo bueno, lo malo y lo incierto de las consultas populares. El Tiempo, http://www.eltiempo.com/colombia/otrasciudades/lo-bueno-lo-malo-y-lo-incierto-de-las-consultas-populares-95264. Recuperado el 13 de marzo de 2018.

Polletta, Francesca. (2006). It was like a fever. Storytelling in Protest and Politics. Chicago: The University Chicago Press.

Polletta, Francesca y Chen, Bobby. (2017). Narrative and Social Movements. The Oxford Handbook of Cultural Sociology. Oxford, New York: Oxford University Press. https://doi.org/10.1093/oxfordhb/9780195377767.013.18

Renauld, Martin. (2016). The Esquel effect: political opportunity structure and adaptation mechanisms in anti-mining mobilisation in Argentine Patagonia. Canadian Journal of Development Studies / Revue canadienne d'études du développement, 37(4), 524-40. https://doi.org/10.1080/02255189.2016.1202102

República de Colombia. (2013). Decreto 934 de 2013 [Ministerio de Minas y Energía]. Por el cual se reglamenta el artículo 37 de la Ley 685 del 2001. Mayo 9 de 2013.

Reuters. (25 de abril de 2017). Buscan salida para que regiones en Colombia no veten la minería. El Tiempo, http://www.eltiempo.com/economia/sectores/gobierno-prepara-proyecto-de-ley-para-evitar-veto-a-la-mineria-enregiones-81256. Recuperado el 12 de marzo de 2018.

Roa García, María Cecilia. (2016). Agua, democratización ambiental y fronteras extractivas en Colombia. Documento N. ${ }^{\circ} 291$. Hamburgo: GIGA German Institute of Global and Area Studies. https://rndp.org.co/wp-content/ uploads/2016/09/wp291_roa_0.pdf

Rueda, María Isabel. (27 de junio de 2017). ¿Las consultas populares están usurpando el subsuelo de la Nación? El Tiempo, http://www.eltiempo. com/economia/sectores/consultas-populares-son-una-amenaza-para-elsector-petrolero-102902. Recuperado el 10 de octubre de 2017.

Tilly, Charles. (2002). Stories, Identities, and Political Change. Lanham: Rowman \& Littlefield Publishers.

Verloo, Nanke. (2018). Social-spatial narrative: A framework to analyze the democratic opportunity of conflict. Political Geography, 62, 137-148. https:// doi.org/10.1016/j.polgeo.2017.11.001. 
Villalba Ximena. (3 de diciembre de 2018). Anglogold Ashanti insiste en 'tumbar' consulta popular de Piedras. El Nuevo Día, http://www.elnuevodia.com.co/ nuevodia/tolima/regional/425028-anglogold-ashanti-insiste-en-tumbar-consulta-popular-de-piedras. Recuperado el 10 de diciembre de 2018.

Walter, Mariana y Urkidi, Leire. (2017). Community mining consultations in Latin America (2002-2012): The contested emergence of a hybrid institution for participation. Geoforum, 84, 265-279. https://doi.org/10.1016/j. geoforum.2015.09.007 